\title{
I2Metrix: Những câu hỏi thường gặp của doanh nghiệp - Trung tâm Nghiên cứu Kinh doanh và Hỗ trọ̆ Doanh nghiệp
}

Viết bỏi $B S A$

Hỏi: i2Metrix là gì?

i2Metrix (i2M) là chữ viết tắt của cụm từ "Inclusive Innovation Metrix" - bộ chỉ tiêu đo lường toàn diện năng lực đổi mới sáng tạo.

i2M cũng là phương pháp để các doanh nghiệp và tổ chức tiến hành kiểm đếm và hoàn thiện năng lực đổi mới sáng tạo của mình

Hỏi: Bộ công cụ ìMetrix do ai xây dựng? Xây dụng vào lúc nào? Có được cơ quan nào chứng nhận không?

i2Metrix do Công ty nghiên cứu DHVP Research và Trung tâm Nghiên cứu kinh doanh và Hỗ trợ doanh nghiệp (BSA) cùng phát triển và giới thiệu tới cộng đồng doanh nghiệp vào cuối năm 2013. i2M là sản phẩm hợp tác dựa trên các kêt quả nghiên cứu khoa học quản trị về hoạt động đổi mới sáng tạo của doanh nghiệp do DHVP Research phối hợp cùng Centre for Creativity and Innovation (Trung tâm Đổi mới và Sáng tạo) thuộc Boise State University (Bang Idaho, Hoa Kỳ) triển khai từ 2009 và 20 năm kinh nghiệm thực tiễn hỗ trợ doanh nghiệp của BSA.

Nhóm xây dựng mô hình i2Metrix bao gồm Ông Vương Quân Hoàng (Chủ tịch DHVP), Bà Vũ Kim Hạnh (Giám đốc BSA), Ông Trần Trí Dũng (Chuyên gia DHVP), với sự cố vấn TS. Nancy K. Napier Đại học Boise State (Idaho, Hoa Kỳ), TS. Dolly Samson Đại học quốc tế Stamford (Bangkok, Thái Lan), và hợp tác từ các nhà nghiên cứu tại Hội Ứng dụng Toán học, Viện Toán học Việt Nam, Viện Nghiên cứu Xã hội.

Phương pháp luận và những nhận thức về quá trình ĐMST tại doanh nghiệp được đúc kêt từ kết quả khảo sát i2M với mẫu 19 thành viên Câu lạc bộ Doanh nghiệp Dẫn đầu (LBC) đã được công bố trên tạp chí khoa học quốc tể Asean Journal for Management and Innovation vào tháng 6-2014.

Hỏi: Doanh nghiệp muốn tham gia i2Metrix thì cần đáp úng điều kiện gì?

Doanh nghiệp muốn tham gia chương trình i2Metrix cần đáp ứng 
các tiêu chí sau:

- Là doanh nghiệp có đăng ký kinh doanh theo pháp luật Việt Nam;

- Có hoạt động thực tế;

- Có nhu cầu đo năng lực đổi mới sáng tạo của bản thân doanh nghiệp;

- Do việc đo i2Metrix sẽ được tiến hành hàng năm, để đảm bảo hiệu quả của bộ đo i2M nhóm nghiên cứu khuyến khích doanh nghiệp tham gia nên cam kết gắn bó và hợp tác với chương trình trong thời gian tối thiểu là 3 năm.

- Cam kết cung cấp thông tin chính xác cho nhóm nghiên cứu trong quá trình khảo sát bằng công cụ i2Metrix.

\section{Hỏi: Tham gia i2Metrix thì doanh nghiệp được lọi ích gì?}

Tham gia chương trình i2Metrix sẽ giúp doanh nghiệp nâng cao năng lực cạnh tranh của mình, thông qua các lợi ích sau:

- Hiểu rõ hiện trạng năng lực đổi mới - sáng tạo của mình;

- Có tiêu chí cụ thể để xác định vị thế của doanh nghiệp trong ngành và trên thị trường;

- Có định hướng phân bổ nguồn lực, giải pháp để cải thiện, tăng cường sức cạnh tranh trong tương lai;

- Tạo ra câu chuyện truyền thông chủ động tới người tiêu dùng và thị trường về nỗ lực hoàn thiện sản phẩm, dịch vụ, cải thiện sức cạnh tranh;

- Vận dụng bộ câu hỏi và cách tiếp cận i2M để tự rà soát và xử lý các vấn đề phát trình trong quá trình ĐMST tại doanh nghiệp.

Hỏi: Hiện tại doanh nghiệp tôi đang gặp khó khăn về việc bán sản phẩm ra ngoài thị trường, vấn đềnhân sự,ceũng như quan tâm đến giải pháp tài chính như thu hút vốn đầu tư, thu động vốn,... nếu tham gia đo i2M thì có hỗ trọ̣ giúp doanh nghiệp tôi giải quyết các vấn đề này?

Tham gia i2Metrix giúp khảo sát năng lực ĐMST của doanh nghiệp trong một số lĩnh vực: phát triển sản phẩm, tiếp cận thị trường, xây dựng nguồn nhân lực, sử dụng nguồn lực tài chính, quản trị tri thức và xây dựng văn hóa doanh nghiệp. Trong phạm vi khảo sát i2M, nhóm nghiên cứu không trực tiếp giải quyết các khó khăn cụ thể của doanh nghiệp trong từng linnh vực.

Tuy nhiên trên thực tế với hơn 30 doanh nghiệp đãtham gia khảo sát i2M,thì trong quá trình trao đổi trực tiếp với lãnh đạo các doanh 
nghiệp, các chuyên gia cũng đã nhiều lần cùng với doanh nghiệp xác định được hướng đi và cả giải pháp cụ thể giải quyết một số các khó khăn cho doanh nghiệp ngay trong buổi khảo sát.

Từ kết quả báo cáo của i2 $\mathrm{M}$, cùng với yêu cầu cụ thể của doanh nghiệp, nhóm nghiên cứu sẽ triển khai các giải pháp hỗ trợ giải quyết những vấn đề khó khăn cụ thể của doanh nghiệp trên cơ sở“Họpp đồng tư vấn quản trị kinh doanh” riêng biệt.

\section{Hỏi: Có phải sau khi tham gia chương trình i2Metrix là doanh nghiệp trở nên đổi mới sáng tạo?}

i2Metrix chỉ là phương pháp và công cụ để giúp doanh nghiệp có cái nhìn thực tế về hiện trạng năng lực đồi mới sáng tạo của mình. Như vậy, i2Metrix không đương nhiên biến doanh nghiệp trở nên đổi mới sáng tạo, mà thay vào đó, bộ công cụ này giúp doanh nghiệp có một định hướng rõ ràng và đúng đắn trong việc xác định xem cần làm những gì để nâng cao năng lực đổi mới sáng tạo của doanh nghiệp.

Quyết định tham gia chương trình i2Metrix phản ánh nhận thức tích cực của doanh nghiệp vai trò của năng lực ĐMST trong nâng cao sức cạnh tranh. Những phân tích, đánh giá và thông tin chia sẻ trong quá trình phỏng vấn sâu và trong báo cáo $i 2 \mathrm{M}$ của doanh nghiệp là những đầu vào giá trị cho việc hoạch định và thực thi quản trị ĐMST tại doanh nghiệp.

\section{Hỏi: Việc tham gia chương trình i2Metrix có liên quan gì đến Bằng khen do Bộ Khoa học và Công nghệ cấp hay không?}

Tháng 2/2014, lần đầu tiên Bộ Khoa học và Công nghệ trao tặng Bằng khen Doanh nghiệp HVNCLC Đối Mói Sáng Tạo cho 17 doanh nghiệp tại Lễ công bố HVNCLC 2014. Trong số này, có 13 doanh nghiệp đã tham gia chương trình i2Metrix trước đó.

Kết quả đo năng lực đổi mới sáng tạo của doanh nghiệp từ chương trình i2Metrix là cơ sở để Hội DN HVNCLC đề xuất danh sách trao tặng bằng khen đến Bộ Khoa học và Công nghệ.

Doanh nghiệp tham gia chương trình i2Metrix sẽ nhận được chứng nhận và xếp hạng do BSA, DHVP và đối tác cấp.

\section{Hỏi: i2Metrix đã được sử dụng cho doanh nghiệp nào chưa? Có phải iaMetrix chỉ phù hợp cho các doanh nghiệp lón?}

Tính đến tháng 09/2014, đã có hơn 30 doanh nghiệp tham gia chương trình i2Metrix. Các doanh nghiệp này có quy mô khác nhau (rất nhỏ, nhỏ, vừa, lớn), loại hình khác nhau (doanh nghiệp tư nhân, công ty TNHH, công ty có vốn Nhà nước) và ngành kinh doanh đa dạng: thực phẩm, dược phẩm, sản xuất hàng gia dụng, chế 
biến nông sản, dệt may...

\section{Hỏi: Doanh nghiệp có phải trả chi phí khi tham gia đo i2Metrix không?}

Chương trình i2Metrix là chương trình có thu phí. Trong giai đoạn hiện nay, chi phí này chỉ ở mức tượng trưng, được thu để đảm bảo tính cam kết của doanh nghiệp và trang trải cho việc đi lại, ăn ở của chuyên gia trong quá trình phỏng vấn i2Metrix.

Mức phí cụ thể như sau:

- Doanh nghiệp là hội viên Hội DN HVNCLC, thành viên LBC, các doanh nghiệp thuộc nhóm đặc sản làng nghề: 5 triệu đồng/doanh nghiệp

- Doanh nghiệp khác: 7 triệu đồng/doanh nghiệp

\section{Hỏi: Với mức phí trên thì doanh nghiệp nhận được những gì từ chưong trình?}

Sau buổi phỏng vấn, doanh nghiệp sẽ được cung cấp:

- Báo cáo Đánh giá Năng lực ĐMST của Doanh nghiệp, bao gồm:

- Kết quả đoi2M của doanh nghiệp

- Đánh giá điểm mạnh, yếu của các kích thước ĐMST tại doanh nghiệp

- So sánh độ lệch: giữa kết quả ĐMST của doanh nghiệp với mức tiềm năng, giữa doanh nghiệp với chỉ tiêu chung của ngành (nếu có), giữa doanh nghiệp với độ đo tổng thể i2M

- Gợi ý giải pháp hoàn thiện năng lực ĐMST của chuyên gia i2M

\section{Câu chuyện ĐMST của doanh nghiệp giới thiệu trên} www.VietBuzz.org và www.bsa.org.vn

Đây là câu chuyện về thành tựu ĐMST mà doanh nghiệp tâm đắc hoặc thách thức mà doanh nghiệp đang trăn trở được viết qua lăng kính i2Metrix.

Câu chuyện trước khi được công bố sẽ chuyển để doanh nghiệp đọc, có ý kiến chỉnh sửa. Chỉ công bố khi doanh nghiệp có xác nhận đồng ý bằng văn bản/email.

Câu chuyện sau khi công bố tiếp tục được trên các website tiếp tục được chăm sóc về hiệu ứng truyền thông: chia sẻ trên các diễn đàn, mạng xã hội; ghi nhận ý kiến phản hồi; định hướng trao đổi tích cực.. tạo thành cầu nối giữa doanh nghiệp và công chúng. 


\section{Chứng nhận đã tham gia i2Metrix}

\section{Hỏi: Sau khi đo i2Metrix, các bước tiếp theo là gì?}

i2Metrix chỉ là công cụ giúp doanh nghiệp hoạch định chiến lược đổi mới sáng tạo của mình. Hiệu quả của đổi mới sáng tạo đòi hỏi sự quyết tâm, cam kết và nỗ lực không ngừng trong thực tế hoạt động của doanh nghiệp.

Sau khi thực hiện đo i2Metrix, dựa trên nhu cầu của doanh nghiệp, nhóm nghiên cứu có thể hỗ trợ doanh nghiệp để nâng cao năng lực đổi mới sáng tạo thông qua các chương trình tư vấn, tập huấn, đào tạo riêng...

\section{Hỏi: Trong bối cảnh cạnh tranh quốc tế hiện nay, tính hội nhập của i2Metrix nằm ở điểm nào?}

i2Metrix ra đời với mục tiêu cung cấp một phương pháp hoàn thiện năng lực ĐMST và tăng cường sức cạnh tranh cho doanh nghiệp Việt Nam trong bối cảnh hội nhập quốc tế. Bởi thế, đội ngũ phát triển i2M ngay từ đầu đã gồm các chuyên gia Việt Nam, Hoa Kỳ và châu Âu. Các kích thước, chỉ tiêu, và khái niệm được sử dụng trong i2M phù hợp với các hiểu chung của cộng đồng doanh nghiệp và giới học thuật quốc tế với định hướng ứng dụng không riêng cho doanh nghiệp Việt Nam.

Sau các mẫu khảo sát tại Việt Nam, i2Metrix tiếp tục được giới thiệu và kỳ vọng sẽ được sử dụng bởi các nhóm doanh nghiệp ASEAN và Hoa Kỳ.

Chiến lược phát triển i2Metrix của DHVP Research và BSA là đưa i2Metrix trở thành phương pháp và công cụ đánh giá năng lực ĐMST chung cho cộng đồng doanh nghiệp ASEAN. 
